\title{
EFFECT OF STATIC LOAD ON WEAR BEHAVIOUR OF 0.58\% CARBON STEEL
}

\author{
Sagar Kumar ${ }^{1}$, Vimal Kumar Pathak ${ }_{2}{ }^{\#}$ \\ Malaviya National Institute of Technology, Jaipur - 302017, INDIA ${ }^{1,2}$
}

\begin{abstract}
This study investigates the effect of static load and sliding speed on wear resistance of $0.58 \%$ EN8 carbon steel which comes under the class of medium carbon steel. Experiments are performed under unlubricated conditions in moist air on pin on disk type wear apparatus. In this study, three levels of static load and sliding speed were used for conducting experiments. The results shows that wear increases with increasing the load and sliding speed. Average values of wear are considered for both parameters. In this condition, the effect of load shows greater influence on wear as compared to sliding speed which can result in degradation of material at faster rate than normal condition.
\end{abstract}

\section{KEYWORDS}

Static Load, Sliding speed, carbon steel, wear, pin on disc.

\section{INTRODUCTION}

Of the total tonnage of steel production, about three-fourth are plain carbon steels that are economical as compared to alloy steels. Plain carbon steels have moderate strengths and can resist satisfactorily ordinary temperatures and atmospheres and also are available in large quantities, in quite large variations of shapes and sizes with a much lower cost. Also, carbon steels are widely used for structural component in various applications. Among numerous failure modes related with carbon steel, wear is one of the most important failure modes resulting in damage of material and component performance. Many researchers have explored about wear characteristics of steel components and their real life performance under various conditions [1-5]. Load and sliding velocity are some of important variables for understanding wear mechanisms of material.

Wear is defined as removal of material from solid surfaces as a result of mechanical action. It is a characteristic feature of the wear process that the amount of material removed is quite small. However wear in sliding systems is usually a very slow process that is very steady and continuous [6]. The anomalous situation of wear can be judged by considering economic factors. Whenever surfaces move over each other wear will occur: damage to one or both surfaces, generally involving progressive loss of material. In most cases wear is detrimental, leading to increased clearances between the moving components, unwanted freedom of movement and loss of precision, often vibration, increased mechanical loading and yet more rapid wear and sometimes fatigue failure. Abrasive wear occurs when a hard rough surface slides across a softer surface. It is the loss of material due to hard particles or hard protuberances that are forced against and move along a solid surface [7]. 
International Journal of Advances in Materials Science and Engineering (IJAMSE) Vol.5, No.1, January 2016

Goto and Amamoto [8] have studied the effect of stepwise change in load on friction under dry sliding and concluded that quasi mild wear can be attained under shorter sliding distance at higher loads. Carbon content is also emerged as a factor to influence wear behavior of carbon steel [9]. Also, several studies have been conducted on determining wear behavior carbon steels for varying load [10-12]. Previous studies have been conducted under the conditions of varying load \& unlubricated conditions for different materials. Moreover, in the previous studies the relationship between wear has not been investigated.

Most of machines and their components in operation are usually subjected to varying loads rather than static loads. Previous studies have been conducted under the conditions of constant load under unlubricated conditions for different materials. So, present study involves the effect of friction \& wear resistance on $0.58 \%$ carbon steel material due to changes in load under static load condition with experimental and statistical method analysis.

\section{EXPERIMENTAL DETAILS}

The details of experiments performed in this study are shown in figure 1. Starting with selection of raw EN8 carbon steel cylindrical pin. After that weight chemical analysis is performed for finding chemical composition of the material. Preparation of sample is done by implementing various operations like cutting, filling, grinding and surface finishing. As current study is based on understanding the wear behavior of pin, it is advisable to use soft pin material as compared to disk. To verify this, Rockwell hardness test is performed. After that experiments are conducted to study wear behavior using pin on disk apparatus. At last, results are validated by using regression analysis technique.

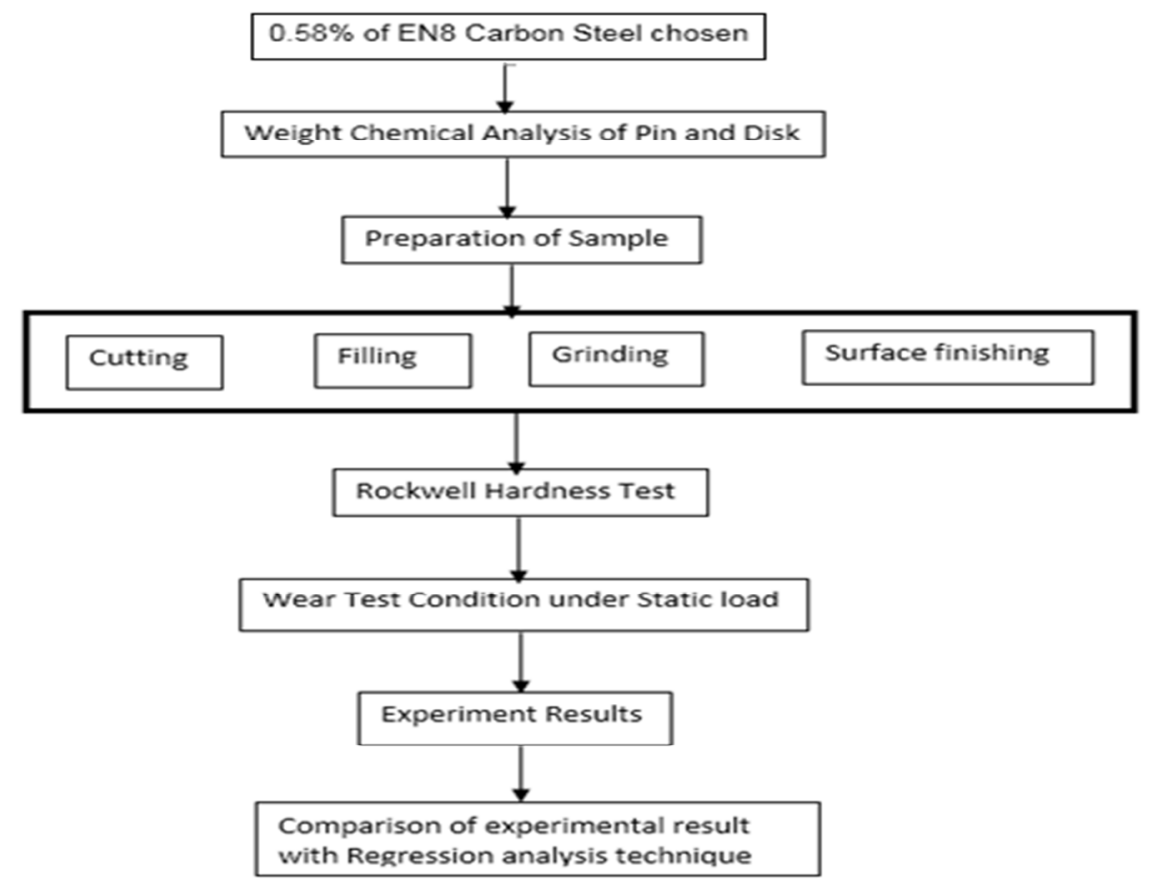

Figure 1. Proposed flowchart for experiment 


\section{MATERIALS AND METHODS}

A pin on disk setup (DUCOM) attached with amplifier is used for experiments. In this setup, a pin is located at one end of arm against rotating disk which is connected with an amplifier. This machine helps in studying friction and wear behavior under static load conditions. Sliding occurs between the stationary pin on a rotating disc. Normal load and wear track diameter can be varied to suit the test conditions. Tangential friction force and wear are monitored with electronic sensors and displayed on front panel. Table 1 depicts the specification of pin on disk apparatus.
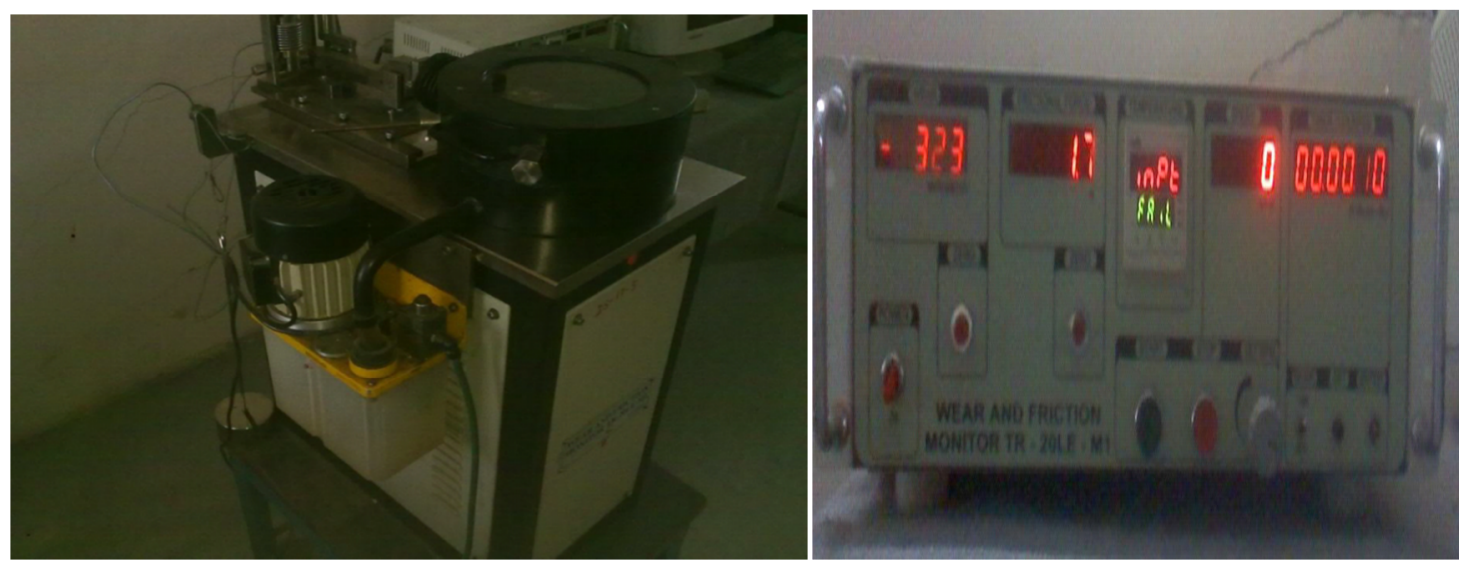

Figure 2. Pin on disk type friction and wear apparatus

Figure 3. Amplifier

Table 1. Specification of pin on disc wear apparatus

\begin{tabular}{|c|c|c|}
\hline S. No. & Parameter & Nominal value \\
\hline 1 & Power & 500VA \\
\hline 2 & Sliding speed range & $0.26 \mathrm{~m} / \mathrm{sec}$ to $10 \mathrm{~m} / \mathrm{sec}$ \\
\hline 3 & Disc rotation speed & $100-2000 \mathrm{RPM}$ \\
\hline 4 & range & 200N Maximum \\
\hline 5 & Normal load & $0-200 \mathrm{~N}$ \\
\hline 6 & Friction force & Up to $4 \mathrm{~mm}$. \\
\hline 7 & $\begin{array}{c}\text { Wear measurement } \\
\text { range }\end{array}$ & $\begin{array}{c}3 \mathrm{~mm} \text { to } 12 \mathrm{~mm} \text { diagonal/ } \\
\text { diameter }\end{array}$ \\
\hline 8 & Pin size & $25 \mathrm{~mm} \times 1 \mathrm{~mm}$ \\
\hline 9 & Disc size & $160 \mathrm{~mm} \times 8 \mathrm{~mm}$ \\
\hline 10 & $\begin{array}{c}\text { Mean wear track } \\
\text { diameter }\end{array}$ & $140 \mathrm{~mm}$ to $140 \mathrm{~mm}$ \\
& & \\
\hline
\end{tabular}

\subsection{PREPARATION OF SAMPLE}

Disc - The disc used for the experiment was supplied by DUCOM and the hardness of disk is 62 HRC. The chemical composition of pin and disk material is shown below in Table 2 and is derived from weight chemical analysis. The diameter of disk is $165 \mathrm{~mm}$ and thickness is $8 \mathrm{~mm}$. It is counter bored $45^{\circ}$ at $15 \mathrm{~mm}$ distance at the outer periphery for proper clamping of the disk. 
International Journal of Advances in Materials Science and Engineering (IJAMSE) Vol.5, No.1, January 2016

Pin - The pin material used for testing is prepared by selecting raw EN8 carbon steel material. After that weight chemical analysis is performed and chemical composition of pin is reported in Table 2. Sample for wear testing pin is prepared by performing cutting, grinding and finishing operations as shown in figure 4. Cutting operation is performed by using hand hacksaw by fixing material in vice. Grinding operation is performed by abrasive wheel. Surface finishing is performed by using various sizes of grit. Rockwell hardness test results depict 29 HRC of hardness. The Rockwell hardness test method consists of identifying the test material with a diamond cone or a hardened steel ball indenter. The determination of the Rockwell hardness of a material involves the application of a minor load followed by a major load, and then noting the depth of penetration, vis a vis, hardness value directly from the dial, in which harder a material gives a higher value. The diameter and length of pin are $10 \mathrm{~mm}$ and $25 \mathrm{~mm}$ respectively.

Table 2. Chemical Composition of pin and Disk

\begin{tabular}{|l|l|l|l|l|l|l|}
\hline \multicolumn{2}{|l|}{ C } & S & MN & Si & Ni & P \\
\hline Pin & 0.58 & 0.016 & 0.79 & 0.18 & 0.00 & 0.027 \\
\cline { 1 - 3 } Disk & 0.61 & 0.022 & 0.8 & 0.18 & 0.02 & 0.32 \\
\hline
\end{tabular}

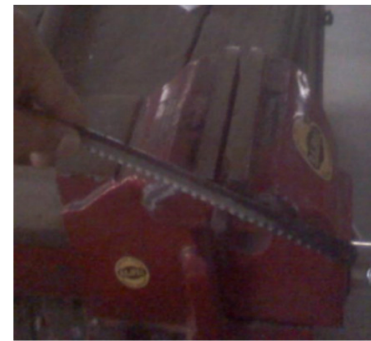

Cutting

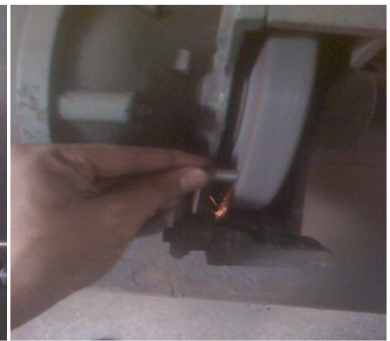

Grinding

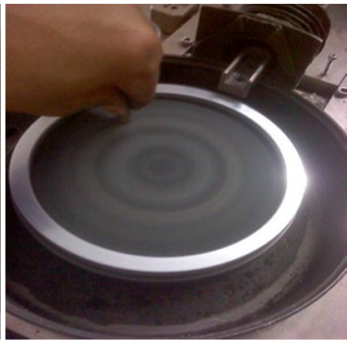

Surface finishing

Figure 4: Steps for sample preparation

\subsection{EXPERIMENT FOR WEAR TESTING}

Before starting the experiments some important points has to be verified to ensure correct readings on amplifier.

Wear - To be preset zero before start of operation.

Friction- To be preset zero before start of operation.

Speed - Speed of the disc variable in the range of $60-2000 \mathrm{rpm}$.

\section{Testing Procedure}

The specimen was polished up to grit $\mathrm{SiC}$ (i.e. paper 1 to 3) abrasive paper to ensure that the wear surface was in complete contact with the abrasive counter face initially and then was cleaned with ethyl alcohol. The cleaned specimen was tightly fixed to the specimen holder or jaw. The parameters were set according to the experimental requirement, such as load, velocity, time, sliding distance etc. The rotational speed was varied for three levels $100 \mathrm{rpm}, 200 \mathrm{rpm}$ and 300 $\mathrm{rpm}$ and the static load condition were $1 \mathrm{~kg}, 2 \mathrm{~kg}, 3 \mathrm{~kg}$. And the whole experiments was performed for ten minutes to know the effects of the above parameters on the wear behaviour. Nine experiments were performed by using above parameter with different levels. The debris was 
International Journal of Advances in Materials Science and Engineering (IJAMSE) Vol.5, No.1, January 2016

carefully collected and preserved for further studies. After that the effect of load and speed is investigated on wear behaviour under different load conditions. The parameter conditions for nine experiments performed on varying speed and static load is shown below in Table 3 .

Table 3. Experimental parameters

\begin{tabular}{|c|c|c|c|}
\hline S. No. & Load $(\mathrm{kg})$ & Sliding Speed $(\mathrm{rpm})$ & Time $(\mathrm{min})$ \\
\hline 1. & 1 & 100 & 10 \\
\hline 2. & 1 & 200 & 10 \\
\hline 3. & 1 & 300 & 10 \\
\hline 4. & 2 & 100 & 10 \\
\hline 5. & 2 & 200 & 10 \\
\hline 6. & 2 & 300 & 10 \\
\hline 7. & 3 & 100 & 10 \\
\hline 8. & 3 & 200 & 10 \\
\hline 9. & 3 & 300 & 10 \\
\hline
\end{tabular}

\section{RESULT AND DISCUSSION}

The experiments were performed under different static load with varying sliding speeds giving the wear behaviour in microns as shown in figure 5, and 6 respectively. In figure 5 , for $100 \mathrm{rpm}$ speed the graph initially showed small rise in wear and after that it is approximately constant and the average value calculated was 137.71 microns. For $200 \mathrm{rpm}$, the graph shows linear wear behaviour initially and after midway it rises rapidly and remains constant after that. For $300 \mathrm{rpm}$, it is reverse as it shows steep rise initially with constant wear behaviour after that. The average wear for 200 and $300 \mathrm{rpm}$ graph is 143.66 and 173.42 microns respectively. Similarly, in figure 6 both the graph are almost linear and the wear is increasing with increasing load and varying speed. The experimental results obtained are reported in Table 4 and the explanation can be understood by bar graph shown in figure 7. The bar graph depicts that the wear behaviour increases with increasing sliding speed and load. In this study, loads are varied one by one. For constant sliding speed, the wear characteristics showed a significant increment by increasing static load from $1 \mathrm{~kg}$ to 2 and $3 \mathrm{~kg}$.

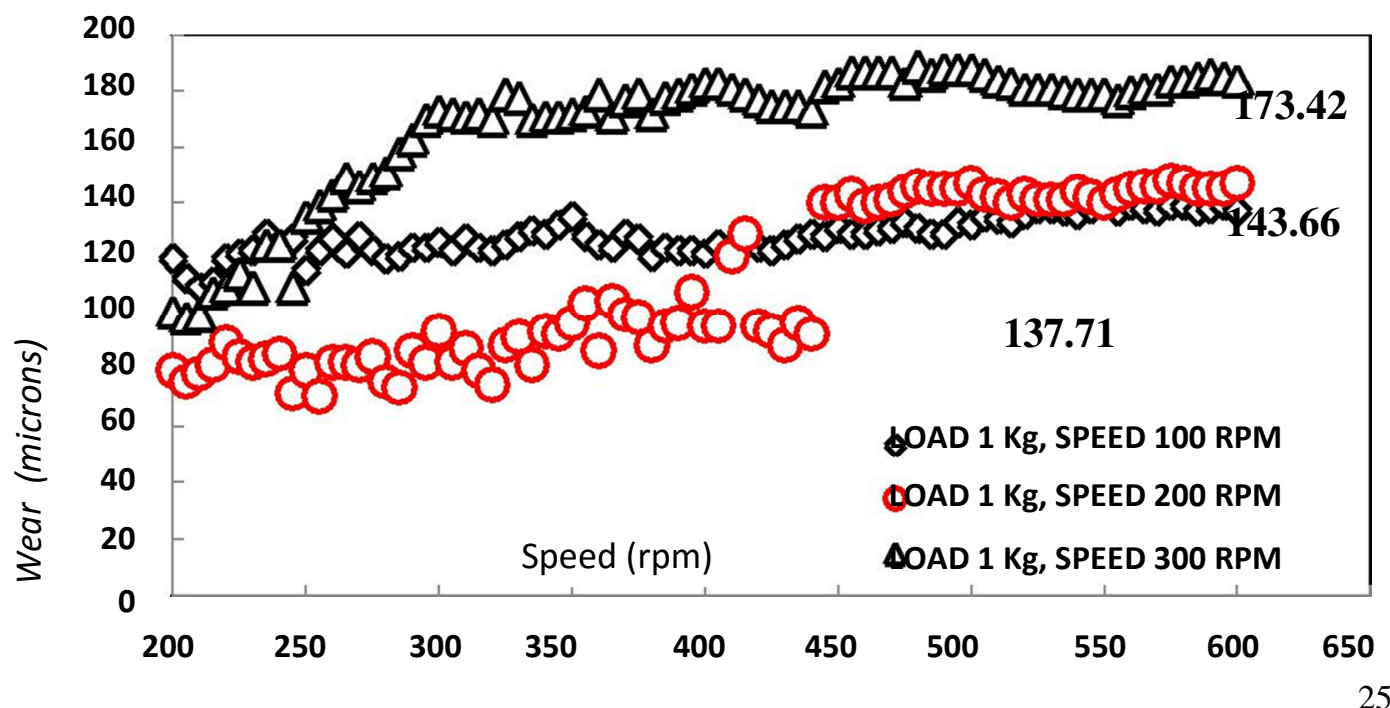


International Journal of Advances in Materials Science and Engineering (IJAMSE) Vol.5, No.1, January 2016
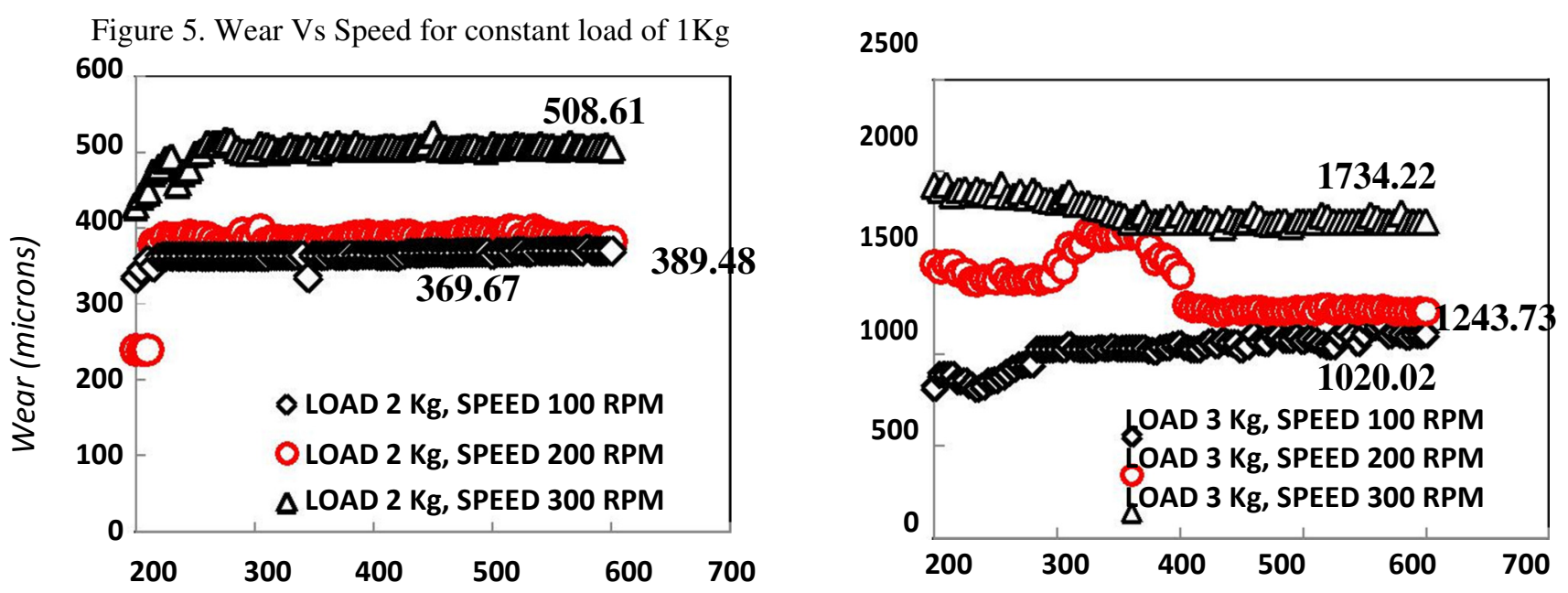

Speed (rpm)

Speed(rpm)

Figure 6. Wear Vs Speed for constant load of $2 \mathrm{Kg}$ and $3 \mathrm{Kg}$

Table 4. Experimental results for wear

\begin{tabular}{|c|c|c|}
\hline Load (kg) & $\begin{array}{c}\text { Speed } \\
(\mathrm{rpm})\end{array}$ & Wear (microns) \\
\hline 1 & 100 & 137.71 \\
\hline 1 & 200 & 143.66 \\
\hline 1 & 300 & 173.42 \\
2 & 100 & 369.67 \\
\hline 2 & 200 & 389.48 \\
\hline 2 & 300 & 508.61 \\
\hline 3 & 100 & 1020.31 \\
\hline 3 & 200 & 1243.73 \\
\hline 3 & 300 & 1734.22 \\
\hline
\end{tabular}

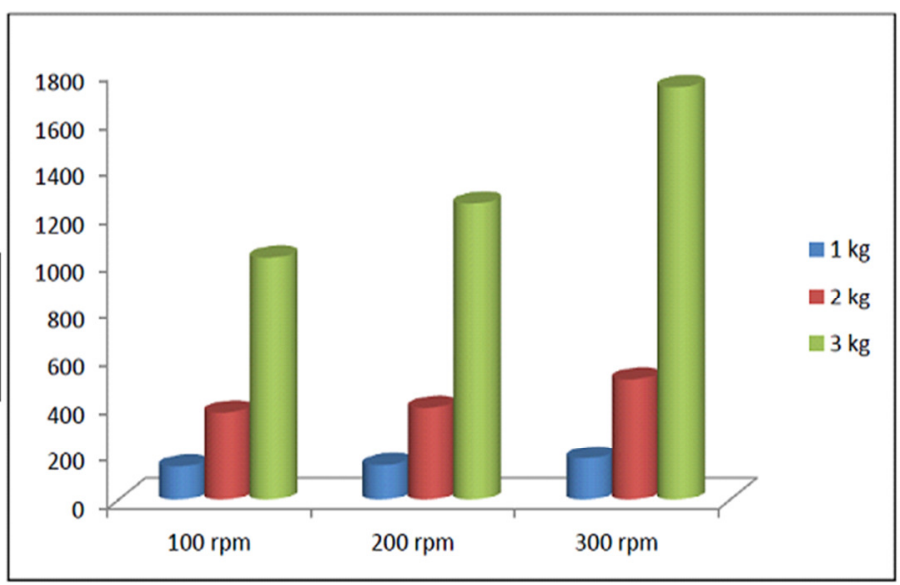

Figure 7. Wear and sliding speed for 1,2 and $3 \mathrm{Kg}$ load 
International Journal of Advances in Materials Science and Engineering (IJAMSE) Vol.5, No.1, January 2016

\section{CONCLUSION}

Pin on Disk type setup is used for conducting experiments for the specimen with $0.58 \%$ carbon steel to study the effect of load and sliding velocity on wear characteristics. The experiments were conducted under unlubricated condition with changing static load one by one between $1 \mathrm{~kg}$ and $3 \mathrm{~kg}$. From the experiment conducted it is found that with increase in load and sliding speed the wear is also increasing but effect of load is more than speed. Wear behaviour of carbon steel is affected by static load and graph shows linear relation between the two. But effect of other parameters is also an issue of discussion like material composition, un-lubricated condition, environmental conditions, hardness etc.

\section{REFERENCES}

[1] Gupta V K and Pandey O P, 2000. Wear Characteristics of Plain Carbon Steel, Indian Journal of Engineering and Materials Science, 7, 354-360.

[2] Tyagi R, Nath S K, Ray S, 2004. Development of wear resistance medium carbon dual phase steel and their mechanical properties [J]. Mat. Sc. Tech, 20, 645-652.

[3] Mohan S, Prakash V, Pathak J P, 2002. Wear Characteristics of HSLA Steel, Wear, 252, 16.

[4] Kaul R., Ganesh P., Tiwari P., Nandedkar R. V., Nath A. K.,2005. Characterization of dry sliding wear resistance of laser surface hardened En 8 steel, Journal of Materials Processing Technology, 167, 83-90.

[5] Amamoto Y, Goto H, 2006. Friction and wear of carbon steel near T1-transition under dry sliding, Tribology International, 39, 756-762.

[6] Bhushan, B, 2000. Tribology: Friction, Wear, and Lubrication, The Engineering Handbook. Ed. Richard C. Dorf Boca Raton: CRC Press LLC.

[7] D. Gates, 1998. Two-body and three-body abrasion: a critical discussion, Wear 214, 139-146.

[8] Goto H, Amamoto Y, 2007. Effect of stepwise change in load on the subsequent friction and wear characteristics of carbon steel under dry sliding. Wear 263, 579-585.

[9] Gupta A K and Mishra D N, 2013. An Experimental investigation of the effect of carbon content on the wear behavior of plain carbon steel, International Journal of Science and Research, 2(7), 222224.

[10] Goto H, Amamoto Y, 2003. Effect of varying load on wear resistance of carbon steel under unlubricated conditions, wear 254, 1256-1266.

[11] Goto H, Amamoto Y, 2011. Improvement of wear resistance for carbon steel under unlubricated sliding and variable loading conditions, wear 270, 725- 736.

[12] Goto H, Amamoto Y, C.V. Suciu, 2009. Investigation on the mechanism of quasi-mild wear for carbon steel in dry sliding contact under variable loading and endurance of the worn surfaces, Wear 267, 505-514.

\section{AUTHORS}

Mr. Sagar Kumar is Ph.D. research scholar in Department ofMechanical Engineering at Malaviya National Institute of Technology, Jaipur. He has done his Masters from VNIT, Nagpur in CAD/CAM. His area of Interests are Tribology, Rapid Tooling, Reverse Engineering and CAD/CAM/CAE.

Mr. Vimal Kumar Pathak is Ph.D. research scholar in Department of Mechanical Engineering at Malaviya National Institute of Technology, Jaipur. He has done his masters from ISM Dhanbad in Maintenance Engineering and Tribology. His area of interests are advanced tribology, Reverse Engineering, Rapid Prototyping, Automatic inspection, Optimization, Geometric Dimensioning and Tolerancing.
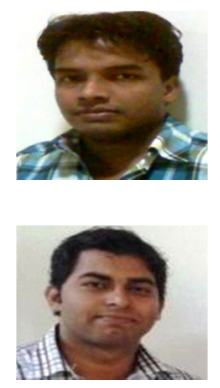